\title{
Accrual Effect on Karachi Stock Exchange
}

\author{
Zaheer Abbas Awan ${ }^{1}$ \\ Muhammad Kashif ${ }^{2}$ \\ Muhammad Waseem Ur Rehman ${ }^{3}$
}

\begin{abstract}
The study examine whether the stock prices can reflect the information of future earnings contained in the accrual components of the current period. The magnitude of accruals component determines the extent to which the current earnings performance persists in the future. However, the current earnings show that the investors hardly reflect the information contained in the accruals components. All listed and non-listed companies (662) on Karachi Stock Exchange, form January 1993 to December 2015 are incorporated in the study. The study concluded that accruals anomaly does not exist in the Karachi Stock Exchange. Which implies that an investor who follows an investment strategy on the basis of accruals will not earn excess returns. Moreover, it implies the Capital Asset Pricing Model is a valid model to capture the effect of accruals.
\end{abstract}

Keywords: Accruals, Anomalies, Karachi Stock Exchange, Future Earnings, Market Efficiency

JEL Classification: G11, G12, G15

\section{INTRODUCTION}

Market's inability to predict the existing pattern always brings an opportunity for investors to earn the excess profit. Accruals and cash flows from operations are important aspects of finance. These two factors are very important for estimating the future earnings. Yet, in the case of Pakistan, there is limited research explaining the properties of the accruals. It is a first comprehensive study which helps the investors to make better decisions. The study emphasizes that only the earnings of a company is not a true measure of its performance. There is a lot of information hidden in the accruals. Adoption of accruals strategy can bring investor excess profit. A common investor forecast future earning of a firm without taking accruals into account. These patterns are hard to predict by using a simple asset pricing model. In this research, we will examine the effect of accruals on stock returns of Karachi Stock Exchange (KSE) using the data of 902 companies from 1993 to 2010. Furthermore, the study uses CAPM to test the efficiency of portfolios on KSE.

\section{Research Problem}

Publically available information of stock may predict the future stock prices. The analysis of the financial statements of the companies can earn excess returns to the investors. Accruals are helpful in determining future earnings. A company following high accruals tends to have low future earnings and a company having low accruals tends to have high future income.

\footnotetext{
${ }^{1}$ MS-Management Sciences Scholar, Shaheed Zulfiqar Ali Bhutto Institute of Science and Technology (SZABIST), Karachi. Email: zaheer059@gmail.com

2 Assistant Professor, Shaheed Zulfiqar Ali Bhutto Institute of Science and Technology (SZABIST), Karachi. Email: mohammadkashif79@yahoo.com

${ }^{3}$ MS-Management Sciences Scholar, Mohammad Ali Jinnah University (MAJU), Karachi. Email: muhammadwaseemurrehman@gmail.com

\begin{tabular}{llll|l}
\hline JISR-MSSE & Volume 14 & Number 1 & Jan-June 2016 & 105
\end{tabular}
}


If accruals exist in KSE then investors will exploit the opportunity of accruals to earn excess profit which implies that CAPM fail to capture the effect of accruals.

\section{Relationship between Accruals and Stock Returns}

There are two types of accounting systems for recording of financial transactions; accrual based system and cash based system. In cash based accounting system the expenses are recorded when they are paid and revenue are recorded when money is received. In accrual based accounting system expense is recorded as it incurred even unpaid. While revenue is recorded when it is realized no matter cash is received or not. There is a negative relationship between accruals and stock returns so as in accruals and future earnings. Here we are talking about accrual base earnings only. Those are the non-cash earnings which have been realized but not yet received. This relation holds on the ground of rationale that a company's accrual income is in doubt. There is no surety that all the accrual earnings will be paid in future. It implies that an investor should take high position with small accrual firms while long position is preferred with the firms having low accruals.

\section{Market Anomalies}

Market anomalies existence is considered to be an indication of inefficient market. The market anomalies are defined as deviation from common or natural pattern George and Elton (2001). The presence of market anomalies is considered as a threat to Efficient Market Hypothesis. There are different types of anomalies few may happen once and disappeared while others may keep on happening. In financial literature the market anomalies are defined as a situation where the stocks show uncommon pattern that are not in line with the basic assumptions of efficient market hypothesis (Silver, 2011).

Anomalies are not general; they occur for specific groups. For them anomalies went right in the beginning but now it is going wrong for them and they are facing the crisis (Kuhn, 1977). Frankfurter and McGoun (2002) found that anomalies occur because social science failed to incorporate the qualitative aspects. Jensen (1978) believes that anomalies exist due to our limitations of data. We face inconsistencies in our old data when new refined data becomes available to us. It also happens because we use the same techniques on new data that we have been using on the previous data. We can better understand the market efficiency by studying the anomalies in details. Watt (1978) argued that abnormal returns are not because of the invalidity of Capital Assets Pricing Model it is due to the inefficiencies of the financial markets.

There are different models given for the explanation of the anomalies but most of them failed to explain anomalies. The famous three factors model of Fama and French (1993) was criticized by Daniel and Titman (1997) that it does not explain momentum effect and longterm effect. There are many classifications of market anomalies. They can be fundamental, technical or Calendar / seasonal. The details of each are as follows:

1. Fundamental Anomalies: Fundamental anomalies are book to market equity, dividend yield, price to sales, and price to earnings (Karz, 2011). 
2. Technical Anomalies: Technical anomalies are those techniques that are used by analysts to predict the future price of a stock using its past price and existing information. Resistance support and moving average are examples of technical anomalies.

3. Calendar or Seasonal Anomalies: Calendar or seasonal anomalies influence the market in particular seasons. For example: Hess (1981) studied that there are high returns on Friday and low return on Monday, it was also found that there exists higher variance on Friday and lowest on Monday. In European markets like Hong Kong and Canada there is low return in the beginning of the week, not only on Monday (Agrawal \& Tendon, 1994).

4. Operating Cash Flow and Accruals as the Determinants of Future Income In estimating the future earning the accruals and cash play a vital role. These are the core components of financial statement analysis. Graham et al. (1962) studied that the current financial information is a key for estimating the future earnings. They followed the five steps for estimating the earning power of an enterprise. The adjustment includes operating accruals, depreciation or amortization and countering for different methods of inventory valuation. The rationale behind the accruals was that there are less chances of recurrence of accruals in future periods.

There were many researchers who believed that, for example: Bernstein (1993) stated that "Cash from operations" is a better measure of future income as compared to "current net income" because the current income is obtained through accrual based accounting system. In accrual system there is a great degree of variation and adjustment while the determinants of cash flow from operations subjected to less variability. The center point here is that the cash flows from operation and accruals have different implications for the estimation of the future earnings. Both of these elements contribute enough in the current earnings. The current earnings are less vital if there is more impact of accruals as compare to cash flow. There are several evidences studied that show the investors usually fail to distinguish between the different predicting power of operating cash flow and accruals. They do not assume that high accruals may result in the suspicious future income. (Bradshaw et al., 2000; Teoh \& wing, 2002).

\section{LITERATURE REVIEW}

There are two schools of through who have opposite views regarding the validity of EMH. One school of thought, on the basis of some empirical results, argues that EMH is invalid. They support their views by presenting the empirical results that show the significant effect of market anomalies on prices. Market anomalies are those movements in the market that are found inconsistent with EMH (Bostanc, 2003). While the other group does admit the existence of market anomalies (Fama, 1990) but they defend the EMH and invalidate the methods used to calculate the returns. They argue that EMH holds but there are imperfections in the model that is used for the computations of the returns (that is CAPM). There are extensive evidences of anomalies in literature. There are two types of anomalies exist in the market (market anomalies and accounting anomalies). The study focuses on the accrual anomaly which is a part of accounting anomaly. There was negative relationship studied between accruals and future earnings (Lewellen, 2014). Which implies that the investor will prefer to invest in the firms that have low accruals because high accruals put the future EPS of a company in doubt. The most prominent work on Accruals was done by 
Sloan (1996). He tested the theory that investors rely heavily on the earning to determine the stock price. They do not take the cash flow of the companies into account. He also studied that the investors ignore the two important aspect of future earnings which are cash flow from operations and accruals. These both elements contribute differently in determination of stock price. When we compare accruals and operating cash flow, the accruals are found to be less persistent. If the investors do not consider the operating cash flow and accruals and only rely on earnings, they may underprice or overprice a stock.

Moreover, Sloan (1996) empirically explained that in US market short position with high accruals firms or long position with low accruals firms will earn positive returns. Sloan further explained that it happens because the investors do not analyze the financial statements and they consider two companies of same earnings but with different accruals. Although, it is fact that high accruals company's earnings may reverse in future. Xie (2001) studied the results consistent with the study of Sloan (1996) and improved upon by adding measure of earnings management. Cheng and Chen (2002) also studied the results in the line with Sloan (1996). They concluded that there is negative association between future abnormal returns and abnormal accruals.

Sloan's work is considered to be a high academic research. Subsequently the researches decomposed accruals into many different elements (i.e. change in working capital, debts, inventory stock and accounts payables) and tested the effect of each component individually. Collins and Hribar (2000) and Thomas and Zhang (2002) followed the same approach, both of the researchers concluded that Sloan's results are linked to accruals which were generated by extreme change in inventory accounts. Thomas and Zhangd (2002) took further step, they tested the effect of material inventories and studied that there is a higher abnormal return associated with change in raw material inventories. Fairfield, Whisenent and Yohn (2003) studied no correlation between accruals and future earnings. They studied the high ratio of accruals will lead to high unproductive assets. They show that when accruals, future earnings, and cash flows are calculated, they are divided by different variables to scale the variables. When the same denominator, which is used for the calculation of accruals and cash flows, is used to compute future earnings, the magnitude of coefficients of accruals and cash flow are found statistically equal.

The relation between the elements of current earnings and future earnings include both variables; cash flows and accruals. Both variables were found to be significant. Cash flows had larger coefficient than accruals, which suggests that accrual mean reversion is faster than the mean reversion of cash flows (Sloan, 1996). In few studies the researchers found accruals effect is diminishing but in general accrual effect is found in many recent and past studies. The vanishing or diminishing effect of accruals is specific with some region or some countries of world.

Richardson et al. (2010) argued that the weak effect of accruals was studied. He concluded that it may be the result that investors have started understanding the effect of accruals and cash flows. Benish and Vargus (2002) argued that one-year return is higher when investment strategy is based on accruals and inside trading then it is based on accruals alone. Deasi et al. (2004) found that the accrual effect disappears when value glamour effect is controlled. Leippold and Lohre (2010) did not study accruals effect in more than 10 countries of total 
26 countries. He concluded that accrual anomalies were found in only few countries. Dechow et al. (2011) came up with a conclusion that accruals are more active either in the countries of common law as compare to civil law countries or in the countries which have accounting system similar to United States. It was further studied that accruals anomaly is weak in the countries that slowly response to the earnings news.

In the light of given literature, it can be concluded that the anomalies do exist in the market and traditional approach of computing returns will not help to capture the effect of market anomalies. The recent studies provided evidence of the existence of the accruals. In this work, we will examine whether the accruals anomaly exists in Karachi Stock Exchange.

\section{RESEARCH METHODOLOGY}

The study is explanatory in nature. The study is a contribution toward the field of portfolio management and asset pricing in Pakistan. The study incorporates monthly bases data for 18 years from January 1993 to December 2015. The study uses both descriptive and inferential statistics to test the consequences of study.

\section{Data and Sampling}

The source of data is "Thomson Reuters". The study collected data of 902 listed companies of Karachi stock exchange from the year 1993 to 2015 . Monthly returns are available on Thomson Reuter's data-stream. The returns are adjusted for the dividend payments. There are two approaches determined in the literature for the calculation of returns; discrete returns and continuous returns. More appropriate return calculation method for the temporal behavior of the asset return is discrete return while continuous return calculation method is more suited for cross sectional returns. To remove the biasness from the estimates we calculate discrete monthly returns.

In 902 companies, the delisted, merged and suspended companies are also included to remove biasness in sample selection. Delisted companies may possess important information therefore, excluding those companies means loss of that information and one-sided data refers to the firms that are doing well in the market. All financial companies are excluded from the sample because they will create one more dimension, due to different features of financial firms and non-financial firms. Shunway (1997) suggested a method to deal with the delisted companies

Table 1.

Summary of the companies before and after applying the filters and criteria from 1991 to 2015

\begin{tabular}{lcc}
\hline Total number of companies available from 1991 to 2010 & 905 & $(100 \%)$ \\
\hline The number of financial firms excluded from the sample firms & & \\
(all banks, modaraba companies, insurance companies and the & & \\
companies that offer financial services) & 243 & $(29 \%)$ \\
Number of Companies left for the analysis & 662 & $(71 \%)$ \\
\hline
\end{tabular}


For the calculation of accruals, there many balance sheet components used. The study used current assets (wc02201), cash and cash equivalents (wc02001), current liabilities (wc03101), depreciation (wc01151), income tax payable (wc03063) and total assets (wc02999). We collected financial data from Thomson Reuters therefore we assigned the Thomson Reuters codes.

\section{Returns, Accruals and Portfolios}

The study uses discrete returns because in continues returns the weighting of portfolios is not possible (Campbell, Lo \& MacKinlay, 1997). There is a large literature suggesting that discrete returns are more appropriate for cross sectional studies. Continuous returns are more suited for the analysis of temporal behavior of asset returns. We incorporate monthly returns instead of daily returns and yearly returns. Because the daily returns have more noise and annual returns neglect the lot of valuable information.

Sloan (1996) was the first to identify the accrual effect. He argued that in forming investing strategies, investors too much rely on the listed income and do not consider accruals, which can have significant effect on income. He tested the accrual effect on stock price and concluded that the companies with low accruals performed better than having high accruals. To calculate accruals, the study uses equation (1) which is widely used formula for accruals calculation in literature (Sloan, 1996; Soares \& Stark, 2009).

Accruals $=\left(\Delta C A_{i, t}-\Delta \operatorname{Cash}_{i, t}\right)-\left(\Delta C L_{i, t}-\Delta S t D e b t_{i, t}-\Delta \operatorname{Div}_{i, t}-\Delta \operatorname{Int}_{i, t}-\right.$ $\left.\Delta \operatorname{Tax}_{i, t}\right)-D e p_{i, t}$

Where; $\Delta C A_{i, t}$ shows change in current assets, $\Delta C a s h_{i, t}$ shows change in cash, $\Delta C L_{i, t}$ shows change in current liabilities, $\Delta S t D e b t_{i, t}$ shows change in short term debt, $\Delta D_{i v_{i, t}}$ shows change in dividend, $\Delta \operatorname{Int}_{i, t}$ shows change in interest, $\Delta \operatorname{Tax}_{i, t}$ shows change in taxes and $D e p_{i, t}$ shows change in depreciation.

Before moving to portfolio formation there are some issues which should be addressed. Portfolio formation is actually classification of data which allow us to make some particular type of analysis (certain characteristics). Usually portfolios are formed on the basis two broad types; those are company based information and market specific information. The market information is more convenient and easily available so it is easy to make monthly portfolios. Portfolios are also formed on the basis of single criterion-based ranking of the assets (Lui et al., 1999; Geogry et al., 2001) or on the basis of two-way ranking of the assets (Miles \& Timmermann, 2006; Fletcher \& Forbes, 2002). We used single way sorting criteria for this study on the basis of accruals. Another important aspect of portfolio construction is to select appropriated method for the calculation of weights those will lead to calculation of weighted return. Generally, value-weighted and equal-weighted returns are calculated and both methods have different aspects. To calculate value weighted returns it is essential to calculate the weights on the basis of market value. Value-weighted return for each portfolio is calculated with the help of equation (2). 
$R_{i, t}^{k}=\frac{\sum_{i=1}^{n} R_{i, t} M V_{i, t-1}}{\sum_{i=1}^{n} M V_{i, t-1}}$

Where; $R_{i, t}^{v w}$ is value-weighted return on portfolio $k, R_{i, t}$ is discrete return on $i^{\text {th }}$ stock at time $t, M V_{i, t-1}$ is a market value of $i^{t h}$ stock at time $t-1$. Another important aspect of portfolio return calculation is the interval of time between $t-1$ and $t$. We calculated the return after one-month interval because it is an appropriate time period. The study constructed pantiles portfolios. First the equally-weighted portfolios are constructed to test the risk adjusted performance of model than value-weighted portfolios are constructed to check the robustness of results.

\section{Econometric Model}

As mentioned above the market anomalies are grouped into two broad groups, market based anomaly and accounting based anomaly. This classification is done because market based anomalies and accounting based anomalies follow different updating time of the weightage scheme portfolio formation. For example, for accounting anomalies, the accounting information is not published at year end and the book value may be available at the year end. Therefore, June value is taken as sorting criteria for the accounting based anomalies while December approach is used for market based anomalies. As our study focuses on the accrual effect on KSE therefore June approach was used in this research.

Black et al. (1972) applied time series regression where he regressed excess return of the portfolio on one or more explanatory variables. The slopes of the regression are risk factors alternatively in the cross-sectional regression of Fama and MacBeth (1973), to explain the cross-sectional variation in the assets return, they used factor loading of time series regression as inputs. Sharp (1964) model can be used to develop understanding of capital assets pricing model.

$\left(R_{i, t}-R_{f}\right)=\beta_{i, M K T}\left(R_{m, t}-R_{f}\right)$

And the time series regression model is:

$\left(R_{p, t}-R_{t}^{f}\right)=\alpha_{i}+\beta_{i, M K T}\left(R_{m, t}-R_{t}^{f}\right)+\varepsilon_{i, t}$

Where; $\left(R_{p, t}-R_{t}^{f}\right)$ is excess return on portfolio which is calculated by taking the deference of portfolio return $R_{p, t}$ and risk free return $R_{t}^{f},\left(R_{m, t}-R_{t}^{f}\right)$ is excess return on market, $\beta_{i, M K T}$ is market risk coefficient, $\alpha_{i}$ is intercept and $\varepsilon_{i, t}$ is stochastic disturbance term. 


\section{Generalized Method of Moments}

Generally, researchers use Ordinary Least Square (OLS) method for the estimation of parameters. (Fama \& French, 1992; Fama \& French, 1993). OLS assumption is multivariate normal return distribution but the stock returns do not follow normal distribution. Stock returns that do not follow the assumption of normality will most likely exhibit coskewness, kurtosis and conditional heteroscedasticity. To overcome these problems generalized method of moments is used. Generalized method of moments (GMM) was introduced by Hansen (1982). The unique feature of GMM is that it does not require the complete knowledge of the distribution of the data. As the assumption of normally distribution does not hold in the stock returns therefore GMM is more suitable than OLS.

GMM is an easy to adopt method that allows to relax the assumption of normality. The other methods that are used to estimate the parameters are Ordinary Least Square, Maximum Likelihood and Generalized Least Square. For the estimation of the alpha (or intercept) of the 5 portfolios (pantiles), the condition of GMM is in equation (5).

$\boldsymbol{R}_{p, t}=\alpha_{p}+\beta_{p} \boldsymbol{F}_{t}+\varepsilon_{i, t} \quad p=1, \ldots, N, \quad t=1, \ldots, T$.

Where; $\boldsymbol{R}_{p, t}$ shows the excess return of the portfolio $i$ at time $t$, while $N$ shows the total number of portfolios which are five in our case, $T$ is a time period of the time series, $\boldsymbol{F}_{t}$ is a vector of dimensions $K$ by 1 portfolio excess returns and $\beta_{p}$ is a vector of covariance (betas). Equation (5) can be written in the following vector form as:

$R_{t}^{x}=\alpha+\beta F_{t}+\varepsilon_{t}, \quad \boldsymbol{E}\left(\varepsilon_{t}\right)=0$ and $\operatorname{cov}\left(F_{t}, \varepsilon_{t}\right), t=1, \ldots, T \ldots$

Where; $R_{t}^{x}=\left[\begin{array}{c}R_{1, t} \\ \vdots \\ R_{5, t}\end{array}\right]$ be the $5 \times 1$ vector containing the excess returns of the stocks sorted in five pantiles portfolios, $\alpha=\left[\begin{array}{c}\alpha_{1} \\ \vdots \\ \alpha_{5}\end{array}\right]$ is the $5 \times 1$ vector carrying the intercepts of the model, $\beta=\left[\begin{array}{ccc}\beta_{1,1} & \ldots & \beta_{1, k} \\ \vdots & \ddots & \vdots \\ \beta_{5,1} & \ldots & \beta_{5, k}\end{array}\right]$ is the $5 \times k$ of portfolios returns sensitive to the market risk factors, $F_{t}=\left[\begin{array}{c}F_{1, t} \\ \vdots \\ F_{k, t}\end{array}\right]$ is $\mathrm{kx} 1$ vector carrying the excess market returns and $\varepsilon_{t}=\left[\begin{array}{c}\varepsilon_{1, t} \\ \vdots \\ \varepsilon_{5, t}\end{array}\right]$ is $5 \times 1$ dimension matrix of stochastic disturbance terms. So, the equation (6) can be written as:

$\left[\begin{array}{c}R_{1, t} \\ \vdots \\ R_{5, t}\end{array}\right]=\left[\begin{array}{c}\alpha_{1} \\ \vdots \\ \alpha_{5}\end{array}\right]+\left[\begin{array}{ccc}\beta_{1,1} & \ldots & \beta_{1, k} \\ \vdots & \ddots & \vdots \\ \beta_{5,1} & \ldots & \beta_{5, k}\end{array}\right]\left[\begin{array}{c}f_{1, t} \\ \vdots \\ f_{k, t}\end{array}\right]+\left[\begin{array}{c}\varepsilon_{1, t} \\ \vdots \\ \varepsilon_{5, t}\end{array}\right] \quad$ where, $\boldsymbol{E}\left(\varepsilon_{t}\right)=0$ and $\operatorname{cov}\left(f_{t}, \varepsilon_{t}\right)$

Let $\boldsymbol{\theta}$ denote set of the unknown parameters $[\alpha, \beta]$. The GMM estimator of $\boldsymbol{\theta}$ minimizes the following quadratic form:

\begin{tabular}{l|llll}
\hline 112 & Jan-June 2016 & Volume 14 & Number 1
\end{tabular}


$\mathrm{g}(\boldsymbol{\theta})^{T} \boldsymbol{W g}(\boldsymbol{\theta}), \quad$ where $\mathrm{g}(\boldsymbol{\theta})=\frac{1}{T} \sum_{t=1}^{T} Z_{t}(\boldsymbol{\theta})$

Where; $\boldsymbol{W}$ is a consistent estimator of weighting matrix. This addresses the issue of autocorrelation and heteroscedasticity. To estimate this estimator Newey and West (1987) procedure is employed. The GMM moment's conditions are defined at the true values of $\alpha$ and $\beta$ as:

$Z_{t}(\boldsymbol{\theta})=\left[\begin{array}{l}\left(R_{t}^{x}-\alpha-\beta F_{t}\right) \\ \left(R_{t}^{x}-\alpha-\beta F_{t}\right) \otimes\left[F_{t}\right]\end{array}\right]$

The efficiency of $F_{t}$ is conditioned upon that the value of $\alpha$ should not be other than zero incase if the return model is true model. Thus, given the time-series of excess returns and factors $\left[R_{t}^{x}, F_{t}\right]_{t=1}^{T}$.

\subsection{Walt Test}

To test our hypothesis whether CAPM is a valid model to explain the risk sensitivity of accruals, we tested the joint statistical significance of all the intercepts. Wald-Test was used to test the joint significance of the hypotheses. Cochrane (2005) shows the asymptotic $\chi^{2}$ which is the standard Wald statistics is used to jointly test the significance of pricing errors. It is defined as:

Wald Statistic $=T[1+C]^{-1} \hat{\mathrm{a}} \boldsymbol{\Psi}^{-1} \hat{\mathrm{a}} \boldsymbol{\Phi} \chi_{N-k}^{2}$

Where $\boldsymbol{\Psi}$ is the variance-covariance matrix for the estimated pricing errors and the characteristics term in $i^{\text {th }}$ row and $j^{\text {th }}$ column are equal to:

$\frac{1}{T} \sum_{t=1}^{T}\left[\hat{\mathrm{a}}_{i, t}-E_{T}\left(\hat{\mathrm{a}}_{i, t}\right)\right]\left[\hat{\mathrm{a}}_{j, t}-E_{T}\left(\hat{\mathrm{a}}_{j, t}\right)\right]$.

Where; $\hat{a}$ is the estimates vector of average cross-sectional pricing errors for each portfolio. The pricing errors for portfolio $i$ is defined as:

$\hat{\mathrm{a}}=\left(R_{t}^{x}\right)-\left(\beta F_{t}\right)$

\section{EMPIRICAL RESULTS}

\section{Preliminary Findings}

The table 2 shows the characteristics of the portfolios. Which were formed on the basis of accruals from January 1993 to December 2015. In the column of EW returns P1 which has low level of accruals, exhibits high returns while the P5 which has high level of accruals, exhibits low returns. The difference between the portfolio of low level of accruals firms and high level of accruals firms is positive. Hence the results of EW returns are in line with the previous researches. Similar pattern is observed in case of VW return. If we compare the 
performance, there is a high return in EW than VW and there is more variation in the extreme portfolios on the basis of EW than VW. The t-value suggest there is no difference between high accruals and low accruals firms. Hence, accruals sorting criteria may not earn excess returns. These descriptive results are not enough to invalidate the accrual-sorting criteria. For further exploration the Time series analysis is performed in next section.

\section{Risk Adjusted Performance}

In this section, we presented the risk adjusted performance of our pantiles portfolios constructed on the basis of accruals. The study uses equation (4) to test the risk adjusted performance with the help of intercept. We regress equation (4) under the GMM framework with NeweyWest procedure. We tested the significance of Jensen's alphas to study the risk adjusted performance of our portfolios. The detailed results are presented in table 3 . The table 3 reveals some very important information. There is a positive difference studied between the alphas of low accruals portfolios and the alphas of high accrual portfolios. It implies that there is positive return between the two extreme accruals portfolios. Furthermore, all portfolios are statistically significant. The portfolio spread is also significant at 0.01 level; therefore, it can be concluded from this finding that our model captures risk on KSE-All index. Conversely, the Wald Chi-square statistic is only significant at 0.1 level. Therefore, the performance of pantiles portfolios is not very much strong. In the context of equally weighted portfolio returns the accruals based strategy works on Karachi Stock Exchange but after the robust results, we study the different evidences.

\section{Robustness Check}

In table 4, the same analysis is done on the portfolios of the value weighted returns. It is to check if there is difference in the output when the returns are modified. The table presents some very important information. In pantiles portfolios there is a positive difference between the alphas of low accruals portfolios and the alphas of high accrual portfolios. It implies that there is positive return between the two extreme accruals portfolios. The significant alpha equal to zero implies there is no excess return. The table statistic shows there is no change in the output. All the alphas of the table 4 are insignificant. Although the value of most of the alphas is positive but statistically insignificant. Again to check the joint significance of alpha Wald-test is applied. The null hypothesis of the test is that the all alpha jointly equal zero. Value of Chi-square in each of the portfolios is insignificant. It implies that there is no equal alpha. Conversely, the portfolios do not bring different returns. The joint significant explain that the formal Capital Asset Pricing Model is enough to explain the returns and enough to capture the risk in the stocks on Karachi Stock Exchange. It also explains that the alphas are jointly same which implies that accrual based strategy will not earn excess profit to the investors. 
Table 2

Performance and characteristics of portfolios constructed on the basis of accruals

\begin{tabular}{lccccccc}
\hline & P1 & P2 & P3 & P4 & P5 & P1-P5 & t-value \\
\hline \multicolumn{7}{c}{ Sample period from January 1993} & to December \\
\hline Avg. Accruals & -8.99 & -6.97 & -5.56 & -4.36 & -2.33 & -6.65 & -136.74 \\
EW Returns (\% p.a.) & 1.2 & 1.19 & 1.96 & 1.57 & 0.54 & 0.66 & 1.11 \\
VW Returns (\% p.a.) & 1.23 & 0.81 & 0.99 & 0.4 & 1.12 & 0.11 & 0.14 \\
MV (million) & 3954.5 & 2768.8 & 2624.5 & 2857.3 & 2211.8 & 1742.7 & 8.2
\end{tabular}

The table 2 presents the characteristic of pantiles accrual portfolios during the period of 1993 to 2015. KSE-All index listed firms' accruals of year t-1 are used as a sorting criteria for construction of portfolios. The excess return on pantiles portfolios is calculated on monthly basis at time t. P1 is the portfolio that contain the stocks with lowest accrual values and P5 contain highest accrual value stocks. P1-P5 is the hedge portfolio return. Portfolios are rebalanced annually. EW return is the annualized return of EW portfolio, VW return is the annualized return of VW portfolio and MV is the average market value of each portfolio. The t-value analyzes the null hypothesis of no difference in returns on P1 and P5. The significance levels of t-statistic at $0.1,0.05$ and 0.01 are 1.65, 1.96 and 2.58 respectively.

Table 3

Alphas of the Equally Weighted Return Portfolios

\begin{tabular}{cccccccc}
\hline & P1 & P2 & P3 & P4 & P5 & P1-P5 & t-value \\
\hline \multicolumn{7}{c}{ Sample period from January 1993 to December 2015} \\
\hline CAPM Alpha & 0.76 & 0.78 & 1.5 & 1.2 & 0.18 & 0.58 & 9.92 \\
& $(9.15)^{* * *}$ & $(9.33)^{* * *}$ & $(18.01)^{* * *}$ & $(14.41)^{* * *}$ & $(2.15)^{* *}$ & $(7.00)^{* * *}$ & $(0.08)^{*}$ \\
\hline
\end{tabular}

The table 3 presents the performance of equally weighted pantiles accrual portfolios constructed on the basis of accruals for the period 1993 to 2015 . KSE-All index listed firms' accruals of year t- 1 are used as a sorting criteria for construction of portfolios. The excess return on pantiles portfolios is calculated on monthly basis at time t. P1 is the portfolio that contain the stocks with lowest accrual values and P5 contain highest accrual value stocks. P1P5 is the hedge portfolio return, which is used to capture the risk sensitivity of accruals on Karachi Stock Exchange. The study uses t-statistic for significance benchmark. The significance levels of t-statistic at $0.1^{*}, 0.05^{* *}$ and $0.01^{* * *}$ are $1.65,1.96$ and 2.58 respectively. The Walt-test analyzes the null hypothesis of no difference in returns on P1 to $\mathrm{P} 5$ portfolios. For the significance of Walt-test, Chi-square and p-value is used.

Table 4

Alphas of the Value Weighted Return Portfolios

\begin{tabular}{|c|c|c|c|c|c|c|c|}
\hline & $\mathrm{P} 1$ & $\mathrm{P} 2$ & $\mathrm{P} 3$ & $\mathrm{P} 4$ & $\mathrm{P} 5$ & P1-P5 & $\mathrm{t}$-value \\
\hline \multicolumn{8}{|c|}{ Sample period from January 1993 to December 2015} \\
\hline CAPM Alpha & $\begin{array}{c}0.63 \\
(1.03)\end{array}$ & $\begin{array}{c}0.09 \\
(0.16)\end{array}$ & $\begin{array}{c}0.27 \\
(0.48)\end{array}$ & $\begin{array}{c}-0.23 \\
(-0.43)\end{array}$ & $\begin{array}{c}0.42 \\
(0.65)\end{array}$ & $\begin{array}{c}0.21 \\
(0.25)\end{array}$ & $\begin{array}{c}1.92 \\
(0.86)\end{array}$ \\
\hline
\end{tabular}

The table 3 presents the performance of value weighted pantiles accrual portfolios constructed on the basis of accruals for the period 1993 to 2015. KSE-All index listed firms' accruals of year t-1 are used as a sorting criteria for construction of portfolios. The excess return on pantiles portfolios is calculated on monthly basis at time t. P1 is the portfolio that contain the stocks with lowest accrual values and P5 contain highest accrual value stocks. P1-P5 is the hedge portfolio return, which is used to capture the risk sensitivity of accruals on Karachi Stock Exchange. The study uses t-statistic for significance benchmark. The significance levels of t-statistic at $0.1 * 0.05 * *$ and $0.01 * * *$ are $1.65,1.96$ and 2.58 respectively. The Walt-test analyzes the null hypothesis of no difference in returns on P1 to P5 portfolios. For the significance of Walt-test, Chi-square and p-value is used. 


\section{CONCLUSION}

The study emphasizes on the accrual based portfolio strategy on Karachi Stock Exchange. The basic purpose of the study is to test the strength of accrual anomaly in capturing the stock risk. First of all, we constructed the portfolios on the basis of accruals. As suggested by the literature that high accruals firms lead to low returns while low accruals firms exhibit high returns (Sloan, 1996). We tested the effect of accruals using the value weighted and equally weighted portfolio returns. The pantiles portfolios were formed on the bases of accrual strategy. Where, P1 portfolio contains the firms with low level of accruals and P5 portfolio contains the firms with high level of accruals. The literature suggests that the CAPM has been failed to capture the effect of anomalies. This encouraged the researchers to modify the formal CAPM model and to come up with more advanced models. Fama and French (1993) three factor model is an example of modified CAPM. We tested the validity of CAPM by using the Wald test. As it was discussed in the methodology section, the Wald test was used to test the joint significance of the pantiles portfolios. This work is a contribution toward the existing literature by testing the effect of accrual as portfolio investment strategy in Karachi stock exchange (KSE). It is a comprehensive study on KSE which includes all the listed and delisted non-financial companies on KSE-All index for the period 1993 to 2010. On the basis of the results it is concluded that the investing strategy based on accruals will not earn excess returns to investors in KSE. In other words, the accrual anomaly does not exist in KSE. Furthermore, the study justifies the role of CAPM in capturing the effect of accruals. It confirms CAPM is a valid model to capture the effect of accruals in case of KSE stocks. The research can be extended by analysis the moments with accruals and comparing the effect of accruals with operating cash flow.

\section{REFERENCES}

Agrawal, A., \& Tandon, K. (1994). Anomalies or illusions? Evidence from stock markets in eighteen countries. Journal of International Money and Finance, 13(1), 83-106.

Beneish, M. D., \& Vargus, M. E. (2002). Insider trading, earnings quality, and accrual mispricing. The Accounting Review, 77(4), 755-791.

Jensen, M. C., Black, F., \& Scholes, M. S. (1972). The capital asset pricing model: Some empirical tests.

Bradshaw, M. T., Richardson, S. A., \& Sloan, R. G. (2001). Do analysts and auditors use information in accruals?. Journal of Accounting Research, 39(1), 45-74.

Campbell, J.Y., Lo, A.W.C. and MacKinlay, A.C., 1997. The Econometrics of Financial Markets (Vol. 2, pp. 149-180). Princeton, NJ: Princeton University press.

Chen, X., \& Cheng, Q. (2002). Abnormal accrual-based anomaly and managers' motivations to record abnormal accruals. Sauder School of Business Working Paper. 
Cochrane, J.H., 2009. Asset Pricing: (Revised Edition). Princeton university press.

Collins, D. W., \& Hribar, P. (2000). Earnings-based and accrual-based market anomalies: one effect or two?. Journal of Accounting and Economics, 29(1), 101-123.

Daniel, K., \& Titman, S. (1997). Evidence on the characteristics of cross sectional variation in stock returns. The Journal of Finance, 52(1), 1-33.

Dechow, P. M., Hutton, A. P., Kim, J. H., \& Sloan, R. G. (2012). Detecting earnings management: A new approach. Journal of Accounting Research, 50(2), 275-334.

Desai, H., Rajgopal, S., \& Venkatachalam, M. (2004). Value-glamour and accruals mispricing: One anomaly or two?. The Accounting Review, 79(2), 355-385.

Fairfield, P. M., Whisenant, J. S., \& Yohn, T. L. (2003). Accrued earnings and growth: Implications for future profitability and market mispricing. The Accounting Review, 78(1), 353-371.

Fama, E. F. (1991). Efficient capital markets: II. The Journal of Finance, 46(5), 1575-1617.

Fama, E. F., \& French, K. R. (1992). The cross?section of expected stock returns. The Journal of Finance, 47(2), 427-465.

Fama, E. F., \& French, K. R. (1993). Common risk factors in the returns on stocks and bonds. Journal of Financial Economics, 33(1), 3-56.

Fama, E. F., \& MacBeth, J. D. (1973). Risk, return, and equilibrium: Empirical tests. The Journal of Political Economy, 607-636.

Frankfurter, G. M., \& McGoun, E. G. (2002). Anomalies in finance: What are they and what are they good for?. International Review of Financial Analysis, 10(4), 407-429.

Gibbons, M. R., \& Hess, P. (1981). Day of the week effects and asset returns. Journal of Business, 579-596.

Graham, B., \& Dodd, D. L. (1934). Security Analysis: Principles and Technique. McGrawHill.

Jensen, M. C. (1978). Some anomalous evidence regarding market efficiency. Journal of Financial Economics, 6(2/3), 95-101.

Kuhn, T. S. (2012). The Structure of Scientific Revolutions. University of Chicago press.

Leippold, M., \& Lohre, H. (2012). Data snooping and the global accrual anomaly. Applied Financial Economics, 22(7), 509-535.

\begin{tabular}{llll|l}
\hline JISR-MSSE & Volume 14 & Number 1 & Jan-June 2016 & 117
\end{tabular}


Lewellen, J. (2010). Accounting anomalies and fundamental analysis: An alternative view. Journal of Accounting and Economics, 50(2), 455-466.

Richardson, S., Tuna, ?., \& Wysocki, P. (2010). Accounting anomalies and fundamental analysis: A review of recent research advances. Journal of Accounting and Economics, 50(2), 410-454.

Sharpe, W. F. (1964). Capital asset prices: A theory of market equilibrium under conditions of risk. The Journal of Finance, 19(3), 425-442.

Shumway, T. (1997). The delisting bias in CRSP data. The Journal of Finance, 52(1), $327-$ 340.

Silver, T. (2011). Making sense of market anomalies. [Online] www. Investopedia.com

Sloan, R. (1996). Do stock prices fully reflect information in accruals and cash flows about future earnings? (Digest summary). Accounting Review, 71(3), 289-315.

Soares, N., \& Stark, A. W. (2011). Is there an accruals or a cash flow anomaly in UK stock returns?. Available at SSRN 1734507.

Teoh, S. H., \& Wong, T. J. (2002). Why new issues and high-accrual firms underperform: The role of analysts' credulity. Review of Financial Studies, 15(3), 869-900.

Thomas, J. K., \& Zhang, H. (2002). Inventory changes and future returns. Review of Accounting Studies, 7(2-3), 163-187.

Watts, R. L. (1978). Systematic 'abnormal' returns after quarterly earnings announcements. Journal of Financial Economics, 6(2), 127-150. 